\title{
Correction to: Eltrombopag is effective in patients with relapse/refractory aplastic anemia—report from a single center in China
}

\author{
Jing Ruan ${ }^{1} \cdot$ Wei Zuo ${ }^{2} \cdot$ Miao Chen ${ }^{1} \cdot$ Chen Yang ${ }^{1} \cdot$ Bing Han ${ }^{1}$ \\ Published online: 2 November 2020 \\ (C) Springer-Verlag GmbH Germany, part of Springer Nature 2020
}

Correction to: Annals of Hematology. https://doi.org/10.1007/s00277-020-04266-1

The article "Eltrombopag is effective in patients with relapse/ refractory aplastic anemia - report from a single center in China", written by Jing Ruan, Wei Zuo, Miao Chen, Chen Yang and Bing Han, was originally published online on September 18, 2020 with Open Access under a Creative Commons Attribution (CC BY) license 4.0. With the authors' decision to cancel Open Access the copyright of the article changed on October 2020 to (C) Springer-Verlag GmbH Germany, part of Springer Nature 2020 with all rights reserved.

The original article has been corrected.

Publisher's note Springer Nature remains neutral with regard to jurisdictional claims in published maps and institutional affiliations.

The online version of the original article can be found at https://doi.org/ 10.1007/s00277-020-04266-1

Bing Han

hanbing_li@sina.com.cn

1 Department of Hematology, Peking Union Medical College Hospital, Chinese Academy of Medical Science and Peking Union Medical College, Beijing 100730, China

2 Department of Pharmacy, Peking Union Medical College Hospital, Chinese Academy of Medical Science and Peking Union Medical College, Beijing 100730, China 